Article

\title{
Catalytic Hydrogenation of the Sweet Principles of Stevia rebaudiana, Rebaudioside B, Rebaudioside C, and Rebaudioside $D$ and Sensory Evaluation of Their Reduced Derivatives
}

\section{Indra Prakash ${ }^{1}$, Mary Campbell ${ }^{2}$ and Venkata Sai Prakash Chaturvedula ${ }^{1, \%}$}

1 Organic Chemistry Department, Global Research and Development, The Coca-Cola Company, One Coca-Cola Plaza, Atlanta, GA 30313, USA; E-Mail: iprakash@coca-cola.com

2 Product Development, Coca-Cola North America Division, The Coca-Cola Company, One Coca-Cola Plaza, Atlanta, GA 30313, USA; E-Mail: marycampbell@coca-cola.com

* Author to whom correspondence should be addressed; E-Mail: vchaturvedula@coca-cola.com; Tel.: +1-404-676-9257; Fax: +1-404-598-9257.

Received: 8 October 2012; in revised form: 6 November 2012 / Accepted: 8 November 2012 / Published: 16 November 2012

\begin{abstract}
Catalytic hydrogenation of rebaudioside B, rebaudioside C, and rebaudioside D; the three ent-kaurane diterpene glycosides isolated from Stevia rebaudiana was carried out using $\mathrm{Pd}(\mathrm{OH})_{2}$. Reduction of steviol glycosides was performed using straightforward synthetic chemistry with the catalyst $\mathrm{Pd}(\mathrm{OH})_{2}$ and structures of the corresponding dihydro derivatives were characterized on the basis of $1 \mathrm{D}$ and $2 \mathrm{D}$ nuclear magnetic resonance (NMR) spectral data indicating that all are novel compounds being reported for the first time. Also, the taste properties of all reduced compounds were evaluated against their corresponding original steviol glycosides and sucrose.
\end{abstract}

Keywords: ent-kaurane diterpene glycosides; catalytic hydrogenation; $\mathrm{Pd}(\mathrm{OH})_{2}$; structure characterization; spectral data; sensory evaluation

\section{Introduction}

Rebaudioside $\mathrm{B}$, rebaudioside $\mathrm{C}$, and rebaudioside $\mathrm{D}$ are the minor constituents isolated from the leaves of Stevia rebaudiana Bertoni (family: Asteraceae). These compounds are the glycosides of the 
diterpene steviol, ent-13-hydroxykaur-16-en-19-oic acid [1]. Rebaudioside B tastes about 150 times sweeter than sucrose; rebaudioside $\mathrm{C}$ tastes about 20-30 times sweeter than sucrose, and rebaudioside D tastes about 200-220 times sweeter than sucrose; all are non-caloric. Rebaudioside B (1) has a (2-O- $\beta$-D-glucopyranosyl-3-O- $\beta$-D-glucopyranosyl)- $\beta$-D-glucopyranosyl unit at the $C-13$ position with a free carboxylic acid group at the $C$-19 position of the aglycone steviol; whereas rebaudioside $C$ (2) has a (2-O- $\alpha$-L-rhamnopyranosyl-3-O- $\beta$-D-glucopyranosyl)- $\beta$-D-glucopyranosyl unit at the $C$-13 position and a $\beta$-D-glucosyl moiety at the $C-19$ position of the aglycone steviol in the form of an ester; and rebaudioside D (3) has a (2-O- $\beta$-D-glucopyranosyl-3- $O$ - $\beta$-D-glucopyranosyl)- $\beta$-D-glucopyranosyl unit at the $C-13$ position and a $2-O-\beta$-D-glucopyranosyl- $\beta$-D-glucopyranosyl moiety at the $C-19$ position of the aglycone steviol as an ester (Figure 1). As a part of our continuing research to discover natural sweeteners, we have reported several glycosides from the commercial extract of S. rebaudiana [2-9]. Apart from isolating novel compounds from $S$. rebaudiana and utilizing them as possible natural sweeteners or sweetness enhancers, we are also engaged in understanding the physicochemical profiles of steviol glycosides in various systems of interest and structural characterization of their metabolites as well as their synthesis [10-13]. Recently, we have published the catalytic reduction of the three ent-kaurane diterpene glycosides namely rubusoside, stevioside, and rebaudioside A isolated from S. rebaudiana and their sensory evaluation [14]. In this article, we present the synthesis of novel ent-kaurane diterpene glycosides that are prepared by reduction of their $C-16 / C$-17 exocyclic double bond of rebaudioside $\mathrm{B}$, rebaudioside $\mathrm{C}$, and rebaudioside $\mathrm{D}$; their structures were characterized on the basis of extensive nuclear magnetic resonance (NMR) and mass spectroscopic (MS) data as well as enzymatic hydrolysis studies.

Figure 1. Structures of rebaudioside B (1), rebaudioside C (2), and rebaudioside D (3).

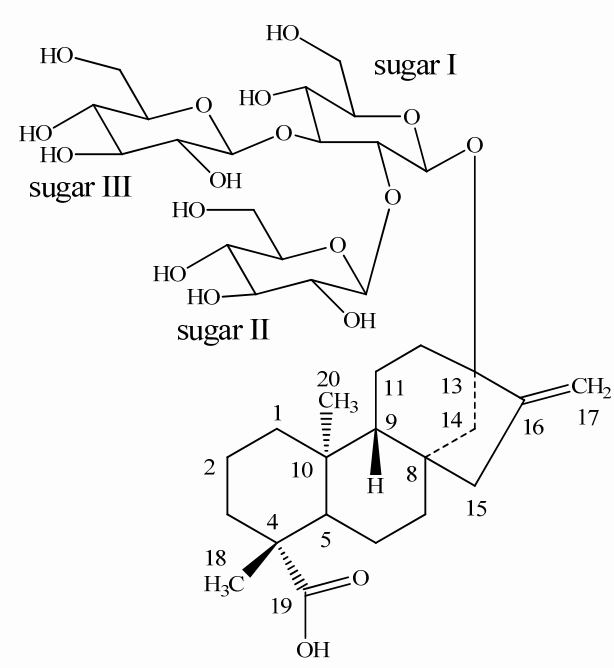

1

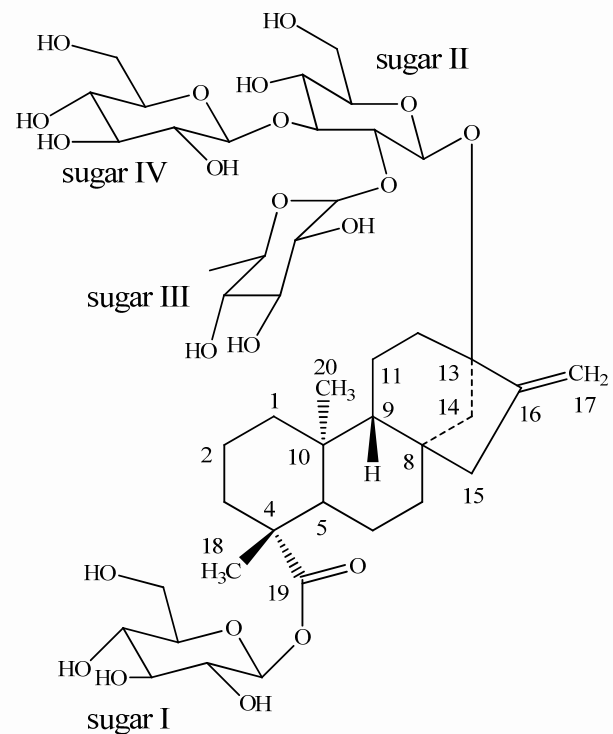

2 
Figure 1. Cont.

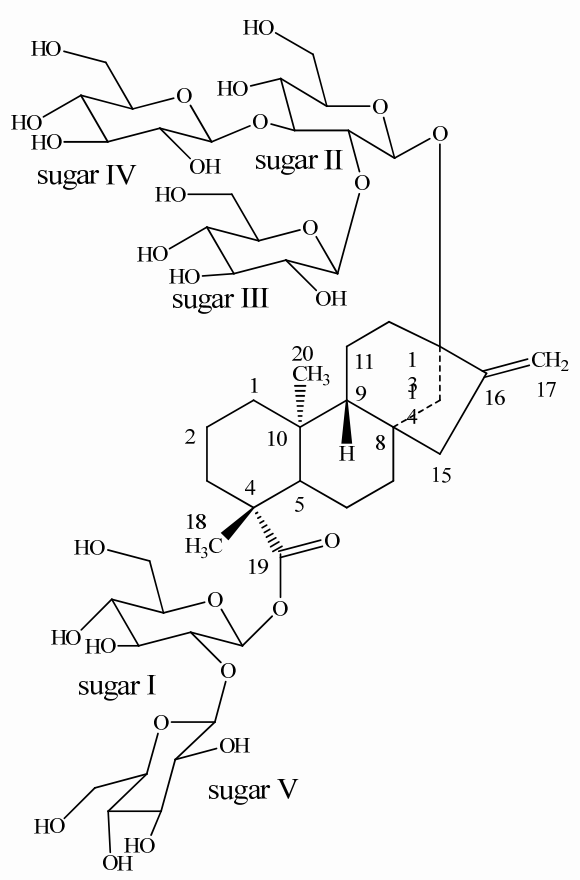

3

\section{Results and Discussion}

2.1. Catalytic Hydrogenation of Rebaudioside B (1), Rebaudioside C (2), and Rebaudioside D (3)

Reduction of the three ent-kaurane diterpene glycosides isolated from $S$. rebaudiana namely rebaudioside $\mathrm{B}$ (1), rebaudioside $\mathrm{C}$ (2), and rebaudioside D (3) was performed using catalytic hydrogenation with $\mathrm{Pd}(\mathrm{OH})_{2}$ in a solvent mixture of $\mathrm{EtOH} / \mathrm{H}_{2} \mathrm{O}(8: 2)$ at room temperature under $55 \mathrm{psi}_{2}$ as reported earlier [14], which furnished mixtures of dihydrorebaudioside-B 1/2 (4/5) (Scheme 1), dihydrorebaudioside-C 1/2 (6/7), and dihydrorebaudioside-D 1/2 (8/9) (Scheme 2). Further trials to separate the mixtures using various separation techniques failed; hence we are reporting the reduced compounds as is.

The ${ }^{1} \mathrm{H}$ and ${ }^{13} \mathrm{C}$ NMR spectral data analysis of the reaction products of rebaudioside $\mathrm{B}$ (1), rebaudioside $\mathrm{C}$ (2), and rebaudioside $\mathrm{D}$ (3) indicated the absence of the exocyclic double bond between $C-16 / C-17$ position and the presence of their corresponding $17 \alpha$ and $17 \beta$ methyl group isomers. The high resolution mass spectral (HRMS) data of the reduced products of rebaudioside B (1), rebaudioside C (2), and rebaudioside D (3) showed 2 amu more than their corresponding starting compounds which supported the hydrogenation. 
Scheme 1. Hydrogenation of rebaudioside B (1) and its reduced compounds.

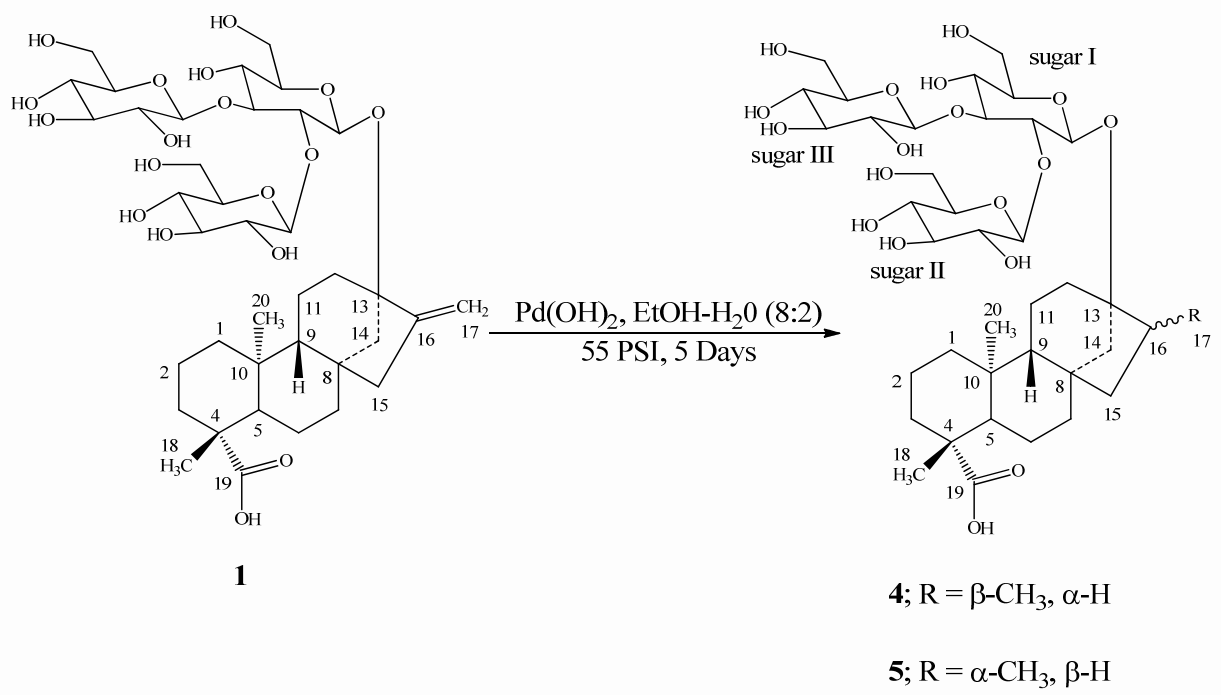

Scheme 2. Hydrogenation of rebaudioside C (2) and rebaudioside D (3) and their reduced compounds.

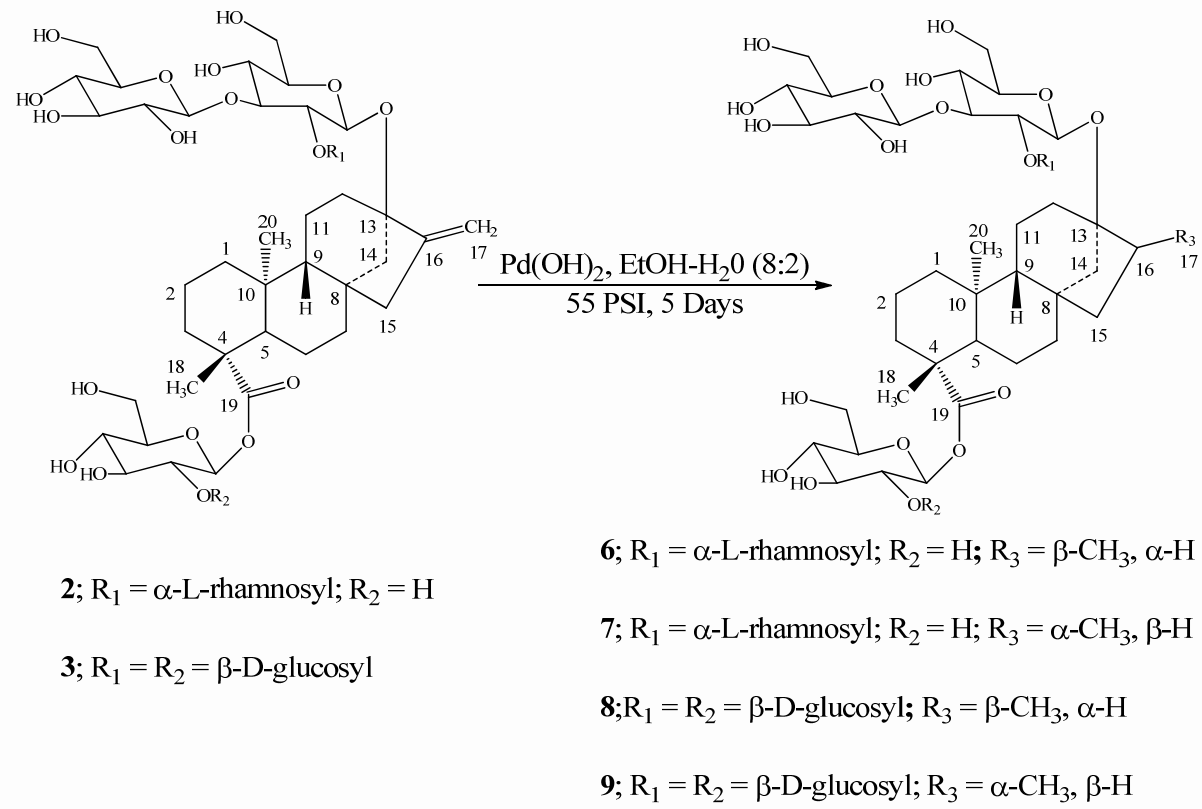

\subsection{Sensory Studies of Reduced Compounds 4-9}

The sensory evaluations of the synthetically reduced steviol glycosides 4-9 at a concentration of $500 \mathrm{ppm}$ were performed against several control samples of $0.75 \%, 2 \%, 4 \%, 6 \%$, and $7.0 \%$ sucrose equivalence (SE) in carbon treated (CT) water at room temperature (rt) as reported earlier [14]. Also, the sensory comparison of the mixtures $4 / 5,6 / 7$, and $8 / 9$ against their original steviol glycosides was studied at $500 \mathrm{ppm}$ using the controlled, multi-sip and swallow taste methods as described below. Sweetness evaluation results indicated that the sweet taste of the hydrogenated rebaudioside B derivatives (4/5) was reduced by over $75 \%$, and that of the rebaudioside D derivatives (8/9) was reduced by about $25 \%$, whereas the rebaudioside $\mathrm{C}$ derivatives $(\mathbf{6} / 7)$ completely lost their sweetness after catalytic reduction (Table 1). These results indicated that the $C 16-C 17$ methylene double bond in steviol glycosides could be regarded as a pharmacophore essential for the sweetness property of these 
molecules $[15,16]$. Similar data has been identified earlier during our study on the catalytic hydrogenation of rubusoside, stevioside, and rebaudioside A [14].

Table 1. Sensory evaluation of rebaudioside B (1), rebaudioside C (2) and rebaudioside D (3) versus catalytically hydrogenated steviol glycosides (4-9) at $500 \mathrm{ppm}$ in CT water at RT.

\begin{tabular}{lll}
\hline Steviol Glycoside Type & Sensory Evaluation of Original Compound & $\begin{array}{l}\text { Sensory Evaluation of } \\
\text { Reduced Compound }\end{array}$ \\
\hline Rebaudioside B (1) & $\begin{array}{l}\text { Slow onset of sweetness, sweet lingering } \\
\text { aftertaste, about 5\%-6\% sucrose equivalence }\end{array}$ & $\begin{array}{l}\text { Weak sweetness, about 1\% } \\
\text { sucrose equivalence }\end{array}$ \\
\hline Rebaudioside C (2) & $\begin{array}{l}\text { Slow onset of sweetness, less sweet overall than } \\
\text { sucrose, about 2\%-3\% sucrose equivalence }\end{array}$ & $\begin{array}{l}\text { No sweetness, moderate } \\
\text { astringency }\end{array}$ \\
\hline Rebaudioside D (3) & $\begin{array}{l}\text { Slow onset of sweetness, very clean, sweeter } \\
\text { overall than sucrose, less sweet lingering } \\
\text { aftertaste compared to sucrose, about 6\%-7\% } \\
\text { sucrose equivalence }\end{array}$ & $\begin{array}{l}\text { Slow onset of sweetness, no } \\
\text { sweet lingering taste, about } \\
5 \%-5.5 \% \text { sucrose equivalence }\end{array}$ \\
\hline
\end{tabular}

\subsection{Spectroscopy and Structural Characterization of Reduced Compounds 4-9}

Structural characterization of the reduced compounds 4-9 obtained by the catalytic hydrogenation of the three ent-kaurane diterpene glycosides isolated from $S$. rebaudiana; rebaudioside B (1), rebaudioside $\mathrm{C}(\mathbf{2})$, and rebaudioside $\mathrm{D}(\mathbf{3})$ was performed on the basis of one-dimensional $\left({ }^{1} \mathrm{H},{ }^{13} \mathrm{C}\right)$, two-dimensional $\left[{ }^{1} \mathrm{H}-{ }^{1} \mathrm{H}\right.$ correlation spectroscopy (COSY), ${ }^{1} \mathrm{H}-{ }^{13} \mathrm{C}$ heteronuclear multiple-quantum correlation (HMQC), ${ }^{1} \mathrm{H}-{ }^{13} \mathrm{C}$ heteronuclear multiple bond correlation spectroscopy (HMBC)] NMR and mass spectral data. The stereochemistry at the $C-16$ position was identified by comparison with their corresponding aglycone derivative NMR values reported in the literature [14,17-19], as well as enzymatic hydrolysis studies. The ${ }^{1} \mathrm{H}-\mathrm{NMR}$ and ${ }^{13} \mathrm{C}-\mathrm{NMR}$ values for all the protons and carbons in dihydrorebaudioside-B1/dihydrorebaudioside-B2 (4/5), dihydrorebaudioside-C1/dihydrorebaudioside-C2 (6/7), and dihydrorebaudioside-D1/dihydrorebaudioside-D2 (8/9) were assigned on the basis of COSY, HMQC and HMBC correlations. Further it was found that the ratio of $17 \alpha / 17 \beta$ reduced compounds was observed to be 3:2 for rebaudioside B (1); and 2:1 for rebaudioside C (2), and rebaudioside D (3). The ${ }^{1} \mathrm{H}-\mathrm{NMR}$ spectral data for the sp3 methyl groups and anomeric protons for the mixture of reduced compounds 4-9 are given in Table 2, whereas the complete assignments of their carbon values are given in Table 3.

Table 2. ${ }^{1} \mathrm{H}$-nuclear magnetic resonance (NMR) chemical shift values for reduced compounds 4-9 recorded in $\mathrm{C}_{5} \mathrm{D}_{5} \mathrm{~N}^{\mathrm{a}-\mathrm{c}}$.

\begin{tabular}{ccccccc}
\hline Position & $\mathbf{4}$ & $\mathbf{5}$ & $\mathbf{6}$ & $\mathbf{7}$ & $\mathbf{8}$ & $\mathbf{9}$ \\
\hline 17 & $1.17(\mathrm{~d}, 6.6,1 H)$ & $1.34(\mathrm{~d}, 6.3,1 H)$ & $1.19(\mathrm{~d}, 6.6,1 H)$ & $1.39(\mathrm{~d}, 6.4,1 H)$ & $1.13(\mathrm{~d}, 6.5,1 H)$ & $1.17(\mathrm{~d}, 6.4,1 H)$ \\
18 & $1.16(\mathrm{~s}, 3 H)$ & $1.18(\mathrm{~s}, 3 H)$ & $1.24(\mathrm{~s}, 3 H)$ & $1.27(\mathrm{~s}, 3 H)$ & $1.14(\mathrm{~s}, 3 H)$ & $1.15(\mathrm{~s}, 3 H)$ \\
20 & $1.19(\mathrm{~s}, 3 H)$ & $1.32(\mathrm{~s}, 3 H)$ & $1.29(\mathrm{~s}, 3 H)$ & $1.28(\mathrm{~s}, 3 H)$ & $1.41(\mathrm{~s}, 3 H)$ & $1.42(\mathrm{~s}, 3 H)$ \\
Sugar I-1' & $5.04(\mathrm{~d}, 6.6,1 H)$ & $5.03(\mathrm{~d}, 6.4,1 H)$ & $6.15(\mathrm{~d}, 6.8,1 H)$ & $6.16(\mathrm{~d}, 6.5,1 H)$ & $6.88(\mathrm{~d}, 6.4,1 H)$ & $6.84(\mathrm{~d}, 6.5,1 H)$ \\
Sugar II-1" & $5.33(\mathrm{~d}, 6.4,1 H)$ & $5.36(\mathrm{~d}, 6.3,1 H)$ & $5.09(\mathrm{~d}, 6.7,1 H)$ & $5.06(\mathrm{~d}, 6.4,1 H)$ & $5.51(\mathrm{~d}, 6.6,1 H)$ & $5.54(\mathrm{~d}, 6.4,1 H)$ \\
Sugar III-1"' & $5.47(\mathrm{~d}, 6.1,1 H)$ & $5.52(\mathrm{~d}, 6.4,1 H)$ & $5.95(\mathrm{~d}, 6.5,1 H)$ & $5.77(\mathrm{~d}, 6.8,1 H)$ & $5.50(\mathrm{~d}, 6.6,1 H)$ & $5.58(\mathrm{~d}, 6.5,1 H)$ \\
\hline
\end{tabular}


Table 2. Cont.

\begin{tabular}{|c|c|c|c|c|c|c|}
\hline Position & 4 & 5 & 6 & 7 & 8 & 9 \\
\hline Sugar IV-1"'" & & & $6.53(\mathrm{~d}, 1.8,1 H)$ & $6.86(\mathrm{~d}, 1.6,1 H)$ & $5.38(\mathrm{~d}, 6.4,1 H)$ & $5.42(\mathrm{~d}, 6.6,1 H)$ \\
\hline Sugar V-1"'"' & & & & & $6.33(\mathrm{~d}, 6.4,1 H)$ & $6.31(\mathrm{~d}, 6.2,1 H)$ \\
\hline Sugar III-6"' & & & $1.65(\mathrm{~d}, 6.1,3 H)$ & $1.74(\mathrm{~d}, 6.4,3 H)$ & & \\
\hline
\end{tabular}

${ }^{\text {a }}$ Assignments made on the basis of correlation spectroscopy (COSY), heteronuclear multiple-quantum correlation (HMQC) and heteronuclear multiple bond correlation spectroscopy (HMBC) correlations; ${ }^{b}$ Chemical shift values are in $\delta$ (ppm); ${ }^{\mathrm{c}}$ Coupling constants are in $\mathrm{Hz}$.

Table 3. ${ }^{13} \mathrm{C}-\mathrm{NMR}$ chemical shift values for reduced compounds $4-9$ recorded in $\mathrm{C}_{5} \mathrm{D}_{5} \mathrm{~N}^{\text {a, b}}$.

\begin{tabular}{|c|c|c|c|c|c|c|}
\hline Position & 4 & 5 & 6 & 7 & 8 & 9 \\
\hline 1 & 40.2 & 40.2 & 41.2 & 41.2 & 41.1 & 41.1 \\
\hline 2 & 20.2 & 20.4 & 20.2 & 20.1 & 20.6 & 20.4 \\
\hline 3 & 38.9 & 38.8 & 38.9 & 39.0 & 38.6 & 38.3 \\
\hline 4 & 44.3 & 43.2 & 44.4 & 43.4 & 44.6 & 42.9 \\
\hline 5 & 57.5 & 56.0 & 58.1 & 57.9 & 58.0 & 57.9 \\
\hline 6 & 23.3 & 23.6 & 22.7 & 23.0 & 23.1 & 22.9 \\
\hline 7 & 41.5 & 40.3 & 41.7 & 40.1 & 41.2 & 40.1 \\
\hline 8 & 44.1 & 43.1 & 44.3 & 43.0 & 43.7 & 42.4 \\
\hline 9 & 56.0 & 50.8 & 56.6 & 54.7 & 55.6 & 54.9 \\
\hline 10 & 40.2 & 40.3 & 40.3 & 40.3 & 40.1 & 40.3 \\
\hline 11 & 20.5 & 20.7 & 20.3 & 20.6 & 20.6 & 20.7 \\
\hline 12 & 35.4 & 44.0 & 35.3 & 44.2 & 35.9 & 44.0 \\
\hline 13 & 88.6 & 88.3 & 86.2 & 86.2 & 88.2 & 88.1 \\
\hline 14 & 47.8 & 50.8 & 47.3 & 50.2 & 47.7 & 50.9 \\
\hline 15 & 47.8 & 44.3 & 47.2 & 44.9 & 47.6 & 44.8 \\
\hline 16 & 41.5 & 38.7 & 41.2 & 39.0 & 41.1 & 38.9 \\
\hline 17 & 16.3 & 16.5 & 14.2 & 19.7 & 14.4 & 17.2 \\
\hline 18 & 29.7 & 29.8 & 28.6 & 28.6 & 29.4 & 29.8 \\
\hline 19 & 180.6 & 180.5 & 177.8 & 177.7 & 176.5 & 176.4 \\
\hline 20 & 15.9 & 16.1 & 15.8 & 16.0 & 15.7 & 15.9 \\
\hline $1^{\prime}$ & 98.6 & 98.8 & 96.2 & 95.7 & 96.2 & 96.2 \\
\hline $2^{\prime}$ & 78.8 & 78.7 & 75.5 & 75.4 & 81.4 & 81.0 \\
\hline $3^{\prime}$ & 85.7 & 86.6 & 79.0 & 79.2 & 78.8 & 78.7 \\
\hline $4^{\prime}$ & 72.1 & 72.2 & 71.4 & 71.4 & 71.5 & 71.4 \\
\hline $5^{\prime}$ & 77.0 & 77.0 & 78.5 & 78.6 & 78.5 & 78.6 \\
\hline $6^{\prime}$ & 62.9 & 62.8 & 62.5 & 62.5 & 63.1 & 63.3 \\
\hline $1 "$ & 105.4 & 105.0 & 98.3 & 96.8 & 94.2 & 94.3 \\
\hline $2^{\prime \prime}$ & 74.6 & 74.6 & 78.4 & 78.6 & 79.1 & 79.2 \\
\hline 3" & 77.8 & 77.8 & 87.1 & 86.1 & 86.0 & 86.7 \\
\hline 4" & 72.1 & 72.3 & 70.6 & 70.5 & 71.2 & 71.1 \\
\hline $5^{\prime \prime}$ & 79.0 & 79.2 & 75.6 & 75.4 & 77.2 & 77.0 \\
\hline 6" & 62.9 & 62.8 & 62.7 & 62.8 & 62.8 & 62.9 \\
\hline $1^{\prime \prime \prime}$ & 105.5 & 105.3 & 103.1 & 102.1 & 105.1 & 104.8 \\
\hline $2^{\prime \prime \prime}$ & 75.6 & 75.7 & 71.7 & 71.6 & 75.7 & 75.9 \\
\hline 3"' & 81.9 & 81.3 & 72.9 & 72.8 & 78.7 & 78.6 \\
\hline
\end{tabular}


Table 3. Cont.

\begin{tabular}{|c|c|c|c|c|c|c|}
\hline Position & 4 & 5 & 6 & 7 & 8 & 9 \\
\hline 4"' & 72.1 & 72.1 & 73.1 & 73.2 & 72.3 & 72.1 \\
\hline $5^{\prime \prime \prime}$ & 79.1 & 79.0 & 70.3 & 70.0 & 79.0 & 79.1 \\
\hline 6"' & 63.1 & 63.3 & 19.4 & 19.3 & 62.5 & 62.8 \\
\hline $1^{\prime \prime \prime \prime}$ & & & 105.0 & 104.9 & 105.3 & 105.9 \\
\hline $2^{\prime \prime \prime \prime}$ & & & 74.9 & 74.7 & 74.3 & 74.4 \\
\hline $3^{\prime \prime \prime \prime}$ & & & 79.8 & 79.7 & 79.8 & 79.9 \\
\hline 4"'"' & & & 72.2 & 72.1 & 72.2 & 72.1 \\
\hline $5^{\prime \prime \prime \prime}$ & & & 79.0 & 78.9 & 79.6 & 79.7 \\
\hline $6^{\prime \prime \prime \prime}$ & & & 63.6 & 63.1 & 63.2 & 63.1 \\
\hline $1 " '+"$ & & & & & 106.1 & 105.4 \\
\hline $2^{\prime \prime " ' "}$ & & & & & 76.8 & 76.7 \\
\hline $3^{\prime \prime " ' "}$ & & & & & 78.9 & 78.8 \\
\hline 4"'"' & & & & & 72.3 & 72.1 \\
\hline $5^{\prime \prime \prime \prime \prime}$ & & & & & 81.8 & 81.4 \\
\hline $6^{\prime \prime " ' "}$ & & & & & 63.5 & 63.5 \\
\hline
\end{tabular}

${ }^{\mathrm{a}}$ Assignments made on the basis of COSY, HMQC and HMBC correlations; ${ }^{\mathrm{b}}$ Chemical shift values are in $\delta$ (ppm).

\section{Experimental Section}

\subsection{General}

Melting points were measured using a SRS Optimelt MPA 100 instrument and are uncorrected. Infrared (IR) spectral data was acquired using a Perkin Elmer 400 Fourier Transform Infrared (FT-IR) Spectrometer (Atlanta, USA) equipped with a Universal Attenuated Total Reflectance (UATR, Atlanta, USA) polarization accessory, whereas NMR spectra were acquired on Varian Unity Plus $600 \mathrm{MHz}$ instrument (Atlanta, USA) in $\mathrm{C}_{5} \mathrm{D}_{5} \mathrm{~N}$ using standard pulse sequences. Chemical shifts were given in $\delta$ (ppm), and coupling constants were reported in Hz. HRMS and MS/MS data were generated with a Waters Premier Quadrupole Time-of-Flight (Q-TOF, New Jersey, USA) mass spectrometer equipped with an electrospray ionization source operated in the positive-ion mode and ThermoFisher Discovery OrbiTrap (New Jersey, USA) in the positive mode of electrospray. All the samples were diluted with water: acetonitrile (1:1) containing $0.1 \%$ formic acid and introduced via infusion using the onboard syringe pump. CT water was prepared by passing water through granular or block carbon material to reduce toxic compounds as well as harmless taste- and odor-producing chemicals.

\subsection{Isolation of Reduced Steviol Glycosides 4-9}

\subsubsection{General Procedure for the Catalytic Hydrogenation of Steviol Glycosides 1-3}

$\mathrm{Pd}(\mathrm{OH})_{2}(50 \mathrm{mg})$ was added to a solution of each steviol glycoside 1-3 $(2 \mathrm{~g})$ in $\mathrm{EtOH} / \mathrm{H}_{2} \mathrm{O}$ $(8: 2,100 \mathrm{~mL})$. The mixture was hydrogenated at ambient temperature for 5 days under hydrogen $\left(\mathrm{H}_{2}\right)$ pressure at 55 psi. After each day, an aliquot of the reaction mixture was filtered through Celite and analyzed by high performance liquid chromatography (HPLC) for the absence of starting materials. At the end of hydrogenation ( 5 days), the reaction mixture was filtered through celite and concentrated 
under vacuum to afford a clear white product. The product was triturated with acetone, filtered and dried under vacuum at $50{ }^{\circ} \mathrm{C}$ for $48 \mathrm{~h}-72 \mathrm{~h}$. The combined purity of each isomeric mixture $\mathbf{4} / \mathbf{5}, \mathbf{6} / \mathbf{7}$, and 8/9 was checked by HPLC and was found to be $>97 \%$.

Dihydrorebaudioside B1/Dihydrorebaudioside B2 (4/5). White powder; IR $v_{\max }: 3347 \mathrm{~cm}^{-1}, 2928$ $\mathrm{cm}^{-1}, 2882 \mathrm{~cm}^{-1}, 1726 \mathrm{~cm}^{-1}, 1034 \mathrm{~cm}^{-1}, 891 \mathrm{~cm}^{-1} ;{ }^{1} \mathrm{H}-\mathrm{NMR}$ and ${ }^{13} \mathrm{C}$-NMR spectroscopic data see Tables 2,3, respectively; HRMS $\left(M+\mathrm{NH}_{4}\right)^{+} m / z 824.4282$ (calcd. for $\mathrm{C}_{38} \mathrm{H}_{66} \mathrm{NO}_{18}$ : 824.4280), $(M+\mathrm{Na})^{+} \mathrm{m} / z$ 829.3838 (calcd. for $\left.\mathrm{C}_{38} \mathrm{H}_{62} \mathrm{O}_{18} \mathrm{Na}: 829.3834\right)$.

Dihydrorebaudioside C1/Dihydrorebaudioside C2 (6/7). White powder; IR $v_{\max }: 3355 \mathrm{~cm}^{-1}, 2932$ $\mathrm{cm}^{-1}, 2881 \mathrm{~cm}^{-1}, 1722 \mathrm{~cm}^{-1}, 1034 \mathrm{~cm}^{-1}, 890 \mathrm{~cm}^{-1} ;{ }^{1} \mathrm{H}-\mathrm{NMR}$ and ${ }^{13} \mathrm{C}-\mathrm{NMR}$ spectroscopic data see Tables 2,3, respectively; HRMS $\left(M+\mathrm{NH}_{4}\right)^{+} m / z 970.4864$ (calcd. for $\mathrm{C}_{44} \mathrm{H}_{76} \mathrm{NO}_{22}$ : 970.4859), $(M+\mathrm{Na})^{+} m / z 975.4418$ (calcd. for $\mathrm{C}_{44} \mathrm{H}_{72} \mathrm{NaO}_{22}$ : 975.4413).

Dihydrorebaudioside D1/Dihydrorebaudioside D2 (8/9). White powder; IR $v_{\max }: 3345 \mathrm{~cm}^{-1}, 2920$ $\mathrm{cm}^{-1}, 2882 \mathrm{~cm}^{-1}, 1724 \mathrm{~cm}^{-1}, 1035 \mathrm{~cm}^{-1}, 880 \mathrm{~cm}^{-1} ;{ }^{1} \mathrm{H}-\mathrm{NMR}$ and ${ }^{13} \mathrm{C}-\mathrm{NMR}$ spectroscopic data see Tables 2,3, respectively; HRMS $(M+\mathrm{H})^{+} m / z 1131.5074$ (calcd. for $\mathrm{C}_{50} \mathrm{H}_{83} \mathrm{O}_{28}$ : 1131.5071), $\left(M+\mathrm{NH}_{4}\right)^{+} m / z$ 1148.5342 (calcd. for $\mathrm{C}_{50} \mathrm{H}_{86} \mathrm{NO}_{28}$ : 1148.5336).

\subsubsection{General Procedure for the Enzymatic Hydrolysis of Reduced Steviol Glycoside Mixtures}

The mixture of each reduced steviol glycoside $(250 \mathrm{mg}$ ) was dissolved in $0.1 \mathrm{M}$ sodium acetate buffer, pH $4.5(50 \mathrm{~mL})$ and crude pectinase from Aspergillus niger (15 mL, Sigma-Aldrich, P2736) was added. The reaction mixture was stirred at $50{ }^{\circ} \mathrm{C}$ for $96 \mathrm{~h}$. The product precipitated out during the reaction for all three mixtures $4 / 5,6 / 7$ and $8 / 9$ was identified as the same based on spectral data and TLC. The filtered compound was purified over silica gel column chromatography; elution with $n$-hexane/acetone $(9.5: 0.5)$ yielded a pure Compound $10\left(18 \mathrm{mg}, \mathrm{mp}: 186{ }^{\circ} \mathrm{C}-190{ }^{\circ} \mathrm{C}\right)$ whereas elution with $n$-hexane/acetone (9.0:1.0) yielded another pure Compound 11 (13 mg, mp: $212{ }^{\circ} \mathrm{C}-214{ }^{\circ} \mathrm{C}$ ). The two Compounds $\mathbf{1 0}$ and $\mathbf{1 1}$ (Figure 2) were identified as dihydrosteviol A and dihydrosteviol B by comparison of their physical and ${ }^{1} \mathrm{H}-\mathrm{NMR}$ spectral data with the literature values [17-19].

Figure 2. Structures of dihydrosteviol A (10) and dihydrosteviol B (11).

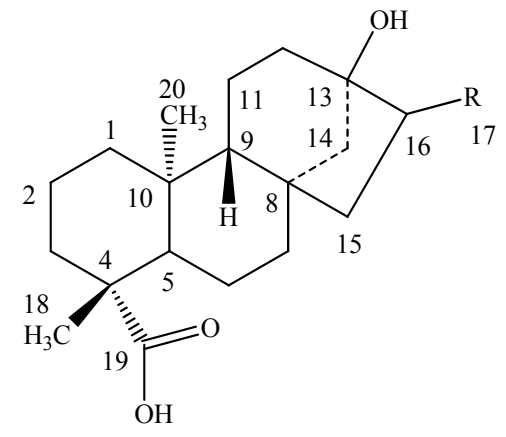

$$
\begin{aligned}
& \text { 10: } R=\beta-\mathrm{CH}_{3} \\
& \text { 11: } R=\alpha-\mathrm{CH}_{3}
\end{aligned}
$$




\subsection{Sweetness Evaluation of the Reduced Steviol Glycoside Mixtures 4-9}

Sweetness evaluation of the reduced steviol glycoside mixtures was performed using sucrose as a control along with their original compounds. Extra fine cane sucrose from Domino (lot\#11:09 6843 1A10) was used for preparation of control samples. Carbon-treated (CT) water was used for all preparations of control, standard steviol glycosides and their reduced compounds. The reduced steviol glycoside mixtures were prepared at $500 \mathrm{ppm}$ for sensory evaluation by adding the non-moisture compensated mass into a $100 \mathrm{~mL}$ sample of CT water. The mixtures were moderately stirred at room temperature (rt), and the reduced steviol glycoside samples were then evaluated against several control sucrose samples at $0.75 \%, 2 \%, 4 \%, 6 \%$ and $7.0 \%$ SE in water at RT by experienced Research and Technology panelists at The Coca-Cola Company, Atlanta, USA, for any tasting quality determinations using the controlled, multi-sip and swallow taste methods shown below.

\subsection{Multi-Sip and Swallow Taste Method}

1. Take first $\operatorname{sip}(\sim 1.8 \mathrm{~mL})$ of a full medicine cup and swallow the control, wait for $15 \mathrm{~s}-25 \mathrm{~s}$, then take the second sip and lock it into memory and wait for $15 \mathrm{~s}-25 \mathrm{~s}$.

2. Taste the first sip of the experimental sample; wait for $15 \mathrm{~s}-25 \mathrm{~s}$, then use the second sip to compare to the second sip of the control.

3. Repeat steps \#1 and \#2 for the third and fourth sips of the same control and experimental samples to confirm the initial finding.

\section{Conclusions}

In conclusion, six ent-kaurane diterpene glycosides 4-9 were synthesized by catalytic hydrogenation of the three natural products rebaudioside B (1), rebaudioside C (2), and rebaudioside D (3) using $\mathrm{Pd}(\mathrm{OH})_{2}$. The structures of all synthesized compounds were characterized on the basis of NMR (1D and 2D) and mass spectral data, enzymatic hydrolysis as well as in comparison with the data reported in the literature. This is the first report of the complete spectral characterization of the reduced compounds of rebaudioside $\mathrm{B}$, rebaudioside $\mathrm{C}$, and rebaudioside $\mathrm{D}$.

\section{Acknowledgements}

We wish to thank the Department of Chemistry, Emory University, Atlanta, GA, USA; Rafael Sa Miguel, Biosciences and Ingredient Department, The Coca-Cola Company, Atlanta, GA, USA for providing sensory data of reduced compounds; and Chris Mubarak, Analytical Sciences Department, The Coca-Cola Company, Atlanta, GA, USA for providing IR spectral data.

\section{Conflict of Interest}

The authors declare no conflict of interest. 


\section{References}

1. Brandle, J.E.; Starrratt, A.N.; Gijen, M. Stevia rebaudiana: Its agricultural, biological and chemical properties. Can. J. Plant Sci. 1998, 78, 527-536.

2. Chaturvedula, V.S.P.; Prakash, I. Diterpene glycosides from Stevia rebaudiana. J. Med. Plants Res. 2011, 5, 4838-4842.

3. Chaturvedula, V.S.P.; Mani, U.; Prakash, I. Diterpene glycosides from Stevia rebaudiana. Molecules 2011, 16, 3552-3562.

4. Chaturvedula, V.S.P.; Prakash, I. A new diterpenoid glycoside from Stevia rebaudiana. Molecules 2011, 16, 2937-2943.

5. Chaturvedula, V.S.P.; Prakash, I. Structures of the novel diterpene glycosides from Stevia rebaudiana. Carbohydr. Res. 2011, 346, 1057-1060.

6. Chaturvedula, V.S.P.; Rhea, J.; Milanowski, D.; Mocek, U.; Prakash, I. Two minor diterpene glycosides from the leaves of Stevia rebaudiana. Nat. Prod. Commun. 2011, 6, 175-178.

7. Chaturvedula, V.S.P.; Prakash, I. Additional minor diterpene glycosides from Stevia rebaudiana. Nat. Prod. Commun. 2011, 6, 1059-1062.

8. Chaturvedula, V.S.P.; Clos, J.F.; Rhea, J.; Milanowski, D.; Mocek, U.; DuBois, G.E.; Prakash, I. Minor diterpenoid glycosides from the leaves of Stevia rebaudiana. Phytochem. Lett. 2011, 4 , 209-212.

9. Chaturvedula, V.S.P.; Mani, U.; Prakash, I. Structures of the novel $\alpha$-glucosyl linked diterpene glycosides from Stevia rebaudiana. Carbohydr. Res. 2011, 346, 2034-2038.

10. Chaturvedula, V.S.P.; Klucik, J.; Mani, U.; Prakash, I. Synthesis of ent-kaurane diterpene glycosides. Molecules 2011, 16, 8402-8409.

11. Chaturvedula, V.S.P.; Clos, J.F.; Prakash, I. Stability study of steviol glycosides in mock beverages using fluorescent light exposure under ICH guidelines. Int. J. Pharm. Pharm. Sci. 2011, 3, 316-323.

12. Chaturvedula, V.S.P.; Clos, J.F.; Prakash, I. Stability of steviol glycosides in mock beverages under acidic conditions. Int. J. Pharm. Pharm. Sci. 2011, 3, 421-425.

13. Prakash, I.; Clos, J.F.; Chaturvedula, V.S.P. Stability of rebaudioside A under acidic conditions and its degradation products. Food Res. Int. 2012, 48, 65-75.

14. Chaturvedula, V.S.P.; Campbell, M.; Miguel, R.I.S.; Prakash, I. Synthesis and sensory evaluation of ent-kaurane diterpene glycosides. Molecules 2012, 17, 8908-8916.

15. Mani, U.; DuBois, G.; Prakash, I. Synthetic study on the relationship between structure and sweet taste properties of steviol glycosides. Molecules 2012, 17, 4186-4196.

16. Kasai, R.; Kaneda, N.; Tanaka, O.; Yamasaki, K.; Sakamoto, I.; Morimoto, K.; Okada, S.; Kitahata, S.; Furukawa, H. Sweet diterpene glycosides of leaves of Stevia rebaudiana Bertoni: Synthesis and structure-sweetness relation of rebaudiosides A, D, and E and their related glycosides. Nippon Kagaku Kaishi 1981, 5, 726-735.

17. Nanayakkara, N.P.D.; Klocke, J.A.; Compadre, C.M.; Hussain, R.A.; Pezzuto, J.M.; Kinghorn, A.D. Characteriztaion and feeding deterrent effects on the aphid, Schizaphis graminum, of some derivatives of the sweet compounds, stevioside and rebaudioside A. J. Nat. Prod. 1987, 50, 434-441. 
18. Pezzuto, J.M.; Compadre, C.M.; Swanson, S.M.; Nanayakkara, N.P.D.; Kinghorn, A.D. Metabolically activated steviol, the aglycone of stevioside, is mutagenic. Proc. Nat. Acad. Sci. USA 1985, 82, 2478-2482.

19. Kamiya, S.; Konishi, F.; Esaki, S. Synthesis and taste of some analogs of stevioside. Agric. Biol. Chem. 1979, 43, 1863-1867.

Sample Availability: Samples of the catalytically reduced steviol glycosides 4-9 are available from the authors.

(C) 2012 by the authors; licensee MDPI, Basel, Switzerland. This article is an open access article distributed under the terms and conditions of the Creative Commons Attribution license (http://creativecommons.org/licenses/by/3.0/). 